\title{
Análise da trajetória institucional de implementação da Política Nacional de Desenvolvimento Regional no
} Brasil

\author{
Sandro Pereira da Silva
}

Instituto de Pesquisa Econômica Aplicada (Ipea)

Este trabalho analisou os processos normativos e arranjos institucionais que são envolvidos na operacionalização de uma política nacional cujo objetivo seja incidir de maneira diferenciada no território nacional, com vistas a promover trajetórias de desenvolvimento mais equilibradas entre as regiões do País. Para isso, foi escolhida como referência analítica a Política Nacional de Desenvolvimento Regional (PNDR), lançada em 2003 pelo Governo Federal. A experiência da PNDR no Brasil pode trazer importantes ensinamentos em termos de arranjos institucionais e federativos necessários para planejar e implementar uma política de desenvolvimento regional voltada para todo o território nacional. No entanto, o desenho institucional da PNDR acarretou fatores que dificultaram uma ação mais consistente para fomentar novas dinâmicas de desenvolvimento nos territórios diferenciados.

Palavras-chave: políticas públicas, desenvolvimento regional, descentralização, participação social

[Artigo recebido em 9 de dezembro de 2014. Aprovado em 28 de abril de 2016.] 
Análisis de la trayectoria institucional de implementación de la Política Nacional de Desarrollo Regional en Brasil

Este estudio analiza los procesos de regulación y arreglos institucionales que participan en la operación de una política nacional cuyo objetivo es enfocar de manera diferente el territorio nacional, con el fin de promover modelos de desarrollo más equilibrado entre las regiones. Para esto, fue elegido como referencia analítica de la Política Nacional de Desarrollo Regional (PNDR), lanzado en 2003 por el gobierno federal. La experiencia de PNDR en Brasil puede aportar lecciones importantes en términos de las disposiciones institucionales y federales necesarias para planificar y poner en práctica una política de desarrollo regional centrado en todo el país. Sin embargo, el diseño institucional de PNDR resultó en factores que obstaculizan una acción más coherente para fomentar nuevas dinámicas de desarrollo en los distintos territorios.

Palabras-clave: políticas públicas, desarrollo regional, descentralización, participación social

\section{Analysis of the institutional trajectory of implementation of the National Policy for Regional Development in Brazil}

This paper analyzed the normative processes and institutional arrangements that are involved in the operation of a national policy whose objective is to intervene differently on national territory, in order to promote more balanced development paths between regions. For this, was chosen as analytical reference the National Policy for Regional Development (PNDR), launched in 2003 by the federal government. The experience of PNDR in Brazil can bring important lessons in terms of institutional and federative arrangements needed to plan and implement a regional development policy focused on throughout the country. However, the institutional design of PNDR resulted in factors that hindered a more consistent action to promote new dynamics of development in the different territories.

Keywords: public policies, regional development, decentralization, social participation 


\section{Introdução}

O Brasil é um país de dimensões continentais, com mais de oito milhões de quilômetros quadrados, estando entre os dez maiores países do mundo em termos de extensão territorial, população e economia. Por outro lado, ele é marcado também por fortes heterogeneidades e desequilíbrios regionais. Tais fatores justificam a defesa de muitos especialistas da necessidade de adoção de políticas de desenvolvimento regional integrado, inseridas em um projeto nacional de longo prazo (СRосомо; GuILhoto, 1998). A questão da definição de escalas espaciais orientadoras do planejamento da ação estatal surge, então, como elemento estratégico nesse debate.

Em termos históricos, a ação deliberada de planejamento estatal teve como marco importante a criação do Ministério do Planejamento em 1962, no Governo do Presidente João Goulart. A primeira pessoa a assumir o ministério foi Celso Furtado, cujas teses fundamentaram as principais ações governamentais de planejamento econômico naquela época e ainda persistem como referências importantes. Furtado confiava no processo político para reverter o quadro perverso de dependência, que gerava desigualdades extremas entre as frações do território brasileiro e era, a seu ver, responsável pelo subdesenvolvimento do País. Por isso, a questão do desenvolvimento regional esteve fortemente presente em sua obra (FURTADO, 2003). Desde então, uma série de planos e programas de investimento estatal foram postos em marcha com vistas a desenvolver a infraestrutura produtiva no País, cujos resultados e consequências estão bem registrados na literatura econômica e política (MINDLIN, 2003).

O que mudou ao longo do tempo foram os instrumentos operacionais de planejamento e intervenção mais recentes, que derivaram de um processo de descentralização e desconcentração do poder político central da União nas últimas décadas. As recentes transformações políticas e econômicas abriram novas frentes de debate em torno da temática do desenvolvimento regional e do planejamento territorial no Brasil, possibilitando alguns avanços, mas também explicitando fortes restrições derivadas do próprio modelo federativo brasileiro.

Este trabalho analisou os processos normativos e arranjos institucionais que são envolvidos na operacionalização de uma política nacional cujo objetivo seja incidir de maneira diferenciada no território nacional, com vistas a promover trajetórias de desenvolvimento mais equilibradas entre as regiões do País. Para isso, foi escolhida como referência analítica a Política Nacional de Desenvolvimento Regional (PNDR), lançada em 2003 pelo Governo Federal, composta por uma série de programas com diferentes escalas territoriais de incidência. Tal política apresenta uma abordagem distinta daquelas adotadas em programas anteriores de desenvolvimento regional, 
ao orientar suas ações com o objetivo de amenizar as disparidades inter e intrarregionais em todo o Brasil.

Neste texto, foram analisados os principais objetivos da PNDR, o ambiente institucional que a envolve no contexto do federalismo brasileiro, as estruturas de governança e participação social em seus territórios de incidência, o método de definição das escalas de planejamento, os instrumentos orçamentários de financiamento dos projetos, a divisão regional dos investimentos e os principais entraves operacionais observados. Para tanto, fez-se uso de revisão bibliográfica sobre temas que possuem relação direta com a PNDR e seus instrumentos de intervenção - tais como federalismo, planejamento, descentralização, políticas públicas e desenvolvimento regional -; documentos oficiais sobre marcos normativos de políticas de desenvolvimento regional - e da PNDR em particular -; além de entrevistas com gestores e técnicos ligados aos programas que compõem a política.

Este texto está organizado em sete seções, contando com esta introdução. A seção dois trata da relação entre Estado, planejamento e políticas regionais, enfatizando os principais aspectos que orientaram a ação estatal no planejamento territorial no Brasil desde a segunda metade do século 20. Na seção três, o debate gira em torno das transformações recentes no cenário sociopolítico nacional, que implicou em novos arranjos de articulação federativa no País. A seção quatro traz um breve relato sobre a emergência do território enquanto conceito orientador da ação estatal, indicando algumas das iniciativas recentes adotadas pelo Governo Federal nesse sentido. A seção seguinte apresenta os principais resultados da pesquisa sobre a Política Nacional de Desenvolvimento Regional no País. Na seção seis, são traçados alguns pontos classificados como limites operacionais para a implementação dessa política. Por fim, são tecidas algumas considerações conclusivas.

\section{Políticas e planejamento territorial no Brasil}

A região, enquanto escala prioritária na definição de projetos de desenvolvimento, representa uma referência associada à localização e à extensão de um determinado fenômeno, correspondendo a entidades espaciais de escala média, entre o nacional e o local. Ela pode ser entendida como uma "subunidade, um subsistema do sistema nacional", que "não tem existência autônoma" em relação ao espaço nacional, "é um subespaço do espaço nacional total" (SANTOS, 1988, p. 46). Nesse caso, para se projetar uma política regional efetiva de âmbito nacional, Galvão e Vasconcelos (1999) apontaram a necessidade de se criarem estratégias que visem: i) criar, nas regiões, um ambiente favorável à atração de investimentos; ii) desenvolver e fortalecer instituições que conduzam a um aumento da capacidade 
de transformação e de aceitação de inovações na base econômica das regiões; e, sobretudo, iii) propiciar um maior grau de coesão interna e de integração espacial dentro das regiões e entre as regiões do país. Ou seja, programas dessa natureza visam dotar regiões com menor dinamismo econômico de condições favoráveis à introdução de inovações para seu desenvolvimento, em lugar do tradicional enfoque de prover subsídios indiscriminados para indústrias ou empresas. Com isso, esperase que o resultado a ser alcançado no médio e longo prazo seja a construção de uma nação mais equilibrada regionalmente.

Para Brandão (2007), as políticas de desenvolvimento com maiores e melhores resultados são aquelas que não discriminam nenhuma escala de atuação e reforçam as ações multiescalares: microrregionais, mesorregionais, metropolitanas, locais, entre outras, contribuindo para a construção de escalas espaciais analíticas e políticas adequadas a cada problema concreto no interior de um território, referente a uma determinada comunidade, a ser diagnosticado e enfrentado.

A definição das formas de concepção de políticas públicas e de atuação governamental baseadas em diferentes escalas e frações de território surgiu no Brasil apoiada em vários aspectos bem característicos do País, entre os quais se encontram: sua dimensão continental marcada por grande heterogeneidade territorial (em termos geográficos, econômicos, sociais); e os complexos processos históricos pelos quais se consolidaram as diferentes identidades regionais. Com base nessa realidade, a questão regional brasileira passou a exigir, para ser eficaz no encaminhamento de soluções, um tratamento apropriado e adequado para os espaços diferenciados. Para Guimarães Neto (2010, p. 49), "se tais desigualdades são marcantes quando se consideram as macrorregiões tradicionais (Norte, Nordeste, Sudeste, Sul e Centro-Oeste), mais significativas se tornam quando se desce à análise dos estados ou de microrregiões no interior do país".

Até a década de 1950, os planos de desenvolvimento nacional praticamente não atendiam à temática regional em programas específicos, de modo que os impactos econômicos dos grandes projetos de investimentos setoriais (indústrias de base, transporte, energia, saúde) se concentravam na Região Sudeste. No plano político, vigorava o modelo nacional-desenvolvimentista, cujos pilares básicos eram: i) Estado intervencionista; ii) planejamento econômico como instrumento basilar do desenvolvimento; e iii) prática do corporativismo como forma de articular as relações entre os principais atores da sociedade e canalizar suas demandas para o Estado (INSTITUto de Pesquisa EConômicA ApliCAdA, 2010a; GoMide, 2012).

A primeira grande ação estratégica no sentido de reorganização do espaço econômico regional e de integração nacional de modo mais equilibrado nessa época foi a criação da Superintendência de Desenvolvimento do Nordeste (Sudene), 
em 1959, no Governo do Presidente Juscelino Kubitschek. A Sudene surgiu como estrutura estatal organizada para coordenar um projeto de desenvolvimento do Nordeste, região com maiores índices de pobreza e carências sociais do País. Após o Golpe Militar em 1964, a Sudene sofreu fortes mudanças no seu projeto original, mas o debate em torno das diferentes escalas de planejamento de políticas permaneceu. Com a expansão da economia pelo território nacional e os investimentos estatais em infraestrutura e exploração de recursos naturais, novas autarquias regionais foram criadas: a Superintendência do Desenvolvimento da Amazônia (Sudam), em 1966, e a Superintendência do Desenvolvimento do CentroOeste (Sudeco), em 1967.

Após um período de forte crescimento econômico e modernização da estrutura produtiva até meados dos anos 1970, o País passou a enfrentar na década seguinte um período de sérias dificuldades fiscais e financeiras que desencadearam a crise do modelo desenvolvimentista em curso. No plano internacional, o colapso do modelo de Breton Woods de gerenciamento econômico internacional e duas crises do petróleo contribuíram significativamente para o esgotamento desse modelo. 0 agravamento das condições macroestruturais da economia brasileira nos anos 1980 acarretou, já no início da década seguinte, pressões para a adoção de políticas de desregulamentação, privatização e liberalização dos mercados, que resultaram em uma reestruturação industrial com forte impacto negativo no mercado de trabalho e em uma nova inserção da economia doméstica no sistema econômico global (GOMIDE, 2012).

Esse novo cenário, fortemente influenciado pela instabilidade pela qual passava o capitalismo mundial, impactou diretamente a condução do planejamento e a perda de capacidade de investimento da estrutura estatal no Brasil. Como consequência, assistiu-se a um desmonte das instituições de planejamento e execução de políticas de desenvolvimento regional, que perderam sua capacidade política de formulação e intervenção no território. A questão regional ficou restrita basicamente à implementação de grandes projetos industriais (metalúrgicos, petroquímicos, energéticos etc.), os quais reconfiguraram o território nacional. As agências regionais, por seu turno, se limitavam a distribuir incentivos fiscais entre grupos econômicos dominantes do cenário local e nacional e a apresentar planos que não chegaram a ser executados em sua maioria.

\section{Descentralização federativa e coordenação da ação pública}

A década de 1980 também foi marcada por sérias alterações no cenário político interno, com a volta da democracia e a promulgação da nova Constituição Federal em 1988; e, na geopolítica global, sobretudo com o fim do bloco soviético. Em 
consequência desse conjunto de acontecimentos tanto no plano nacional quanto internacional, surgiu na década seguinte uma ampla rediscussão sobre o papel do Estado diante desse novo cenário, que viria a definir as principais diretrizes da atuação governamental. Uma das consequências importantes desse momento histórico foi o aprofundamento da descentralização federativa, que passou a delegar ao município um papel mais estratégico no contexto federativo brasileiro para a condução de uma série de políticas.

Segundo Falleti (2006, p. 61-62), descentralização pode ser entendida como um processo de redimensionamento de poder e autonomia no interior do Estado, que envolve um "conjunto de políticas públicas que transfere responsabilidades, recursos ou autoridade de níveis mais elevados do governo para níveis inferiores" (FAlLETI, 2006, p. 60). A partir dessa definição, é possível distinguir entre três categorias de descentralização com base no tipo de autoridade transferida, que são: i) descentralização administrativa: engloba o "conjunto de políticas que transferem a administração e a provisão de serviços sociais como educação, saúde, assistência social e moradia aos governos subnacionais"; ii) descentralização fiscal: refere-se "ao conjunto de políticas desenhadas para aumentar as receitas ou a autonomia fiscal dos governos subnacionais"; e iii) descentralização política: diz respeito ao "conjunto de emendas constitucionais e de reformas eleitorais desenhadas para abrir novos espaços - ou acionar espaços existentes - para a representação das sociedades subnacionais".

Amaral Filho (1999) resumiu os argumentos favoráveis à descentralização da ação pública em três elementos-chave: i) a proximidade e a informação, isto é, os governos locais estão mais próximos dos produtores e dos consumidores finais de bens e serviços públicos e privados, e, por isso, são mais bem informados que os governos centrais a respeito das preferências da população; ii) a experimentação variada e simultânea, ou seja, a diferenciação nas experiências locais pode ajudar a destacar métodos superiores de oferta do serviço público; e iii) o elemento relacionado a tamanho, quer dizer, quanto menor o aparelho estatal, melhor é o resultado de alocação e eficiência.

Essas colocações estiveram fortemente presentes enquanto retórica discursiva no Plano Diretor da Reforma do Aparelho do Estado, lançado pelo Governo Federal em 1995. Com base nessa estratégia, a descentralização era tida como um mecanismo essencial, ao desobrigar a União de uma série de responsabilidades que passariam a ser remetidas ao plano local. Assim, visava-se, por um lado, diminuir o tamanho do Estado central, e, por outro, propiciar ao governo melhores condições para a cobrança de serviços públicos eficientes por parte dos "usuárioscontribuintes". Amaral Filho (1999, p. 1288) classificou esse novo referencial de "modo de intervenção pragmático", uma vez que não se enquadraria em absoluto 
nem no princípio neoliberal, por não aceitar "a crença cega de que o mercado e os preços são os únicos mecanismos de coordenação das ações dos agentes", nem no princípio do dirigismo estatal, "que leva à burocracia pesada, à hierarquia rígida e ao desperdício financeiro".

No entanto, a condução do processo de descentralização adotado no âmbito do Plano Diretor apresentou diversas inadequações, tais como: falta de capacitação das unidades subnacionais para assumir novos encargos; excesso ou insuficiência de controle e acompanhamento das políticas sociais descentralizadas; dificuldade de estruturar ou manter coalizões políticas intrafederativas; incongruência entre o aumento do poder de comando dos governos subnacionais sobre o gasto público e a política de estabilização macroeconômica; e dificuldades para articular a descentralização com as políticas redistributivas interpessoais e inter-regionais (Affonso, 2000). Além disso, o Plano Diretor desconsiderava a necessidade de ações diferenciadas no território nacional que contemplassem as distintas carências das unidades federativas, contribuindo para reforçar o cenário de desigualdades já existente.

A falta de mecanismos de coordenação fez com que os desdobramentos desse processo se resumissem a ações fragmentadas, com poucos resultados em relação à modernização do aparelho estatal burocrático brasileiro. A articulação entre os entes federativos permaneceu na forma de um conjunto superposto de arenas de negociação e coordenação de políticas, ramificadas vertical, horizontal e setorialmente em cada nível de governo ou área de atuação (INSTITUTO DE PESQUISA ECONÔMICA APLICADA, 2010b). Como resultado, acirrou-se no País um cenário de fortes constrangimentos estruturais à pactuação de políticas públicas e estratégias de desenvolvimento (BRANDÃO, 2007).

Para Arretche (2004), estados federativos como o Brasil tendem a passar por maiores "problemas de coordenação dos objetivos das políticas, gerando competição entre os diferentes níveis de governo". Essas relações competitivas desencadeiam processos de "barganhas federativas", nos quais cada nível de governo busca garantir para si os benefícios e transferir a outros os custos políticos. Por isso, a capacidade de engendrar estratégias possíveis para a coordenação vertical de políticas nacionais está diretamente relacionada com o modo pelo qual se estruturam as relações federativas nas políticas setoriais. Os resultados desse limite em termos de coordenação institucional por parte do governo são: "superposição de ações; desigualdades territoriais na provisão de serviços; e mínimos denominadores comuns nas políticas nacionais" (ARRETCHE, 2004, P. 17).

Outro fator que compromete a articulação federativa diz respeito à desigualdade na capacidade de arrecadação. Entre os municípios de cada estado se observa 
uma disparidade muito grande quanto a receitas tributárias, o que precisa ser compensado por meio de transferências fiscais da União. Como consequência, o fato de o Executivo federal ser o maior financiador de políticas no contexto federativo brasileiro, com estados e municípios extremamente dependentes de seus recursos, confere-lhe o principal instrumento de coordenação de que dispõe para influenciar e condicionar as escolhas dos governos locais (ARRETCHE, 2004). Porém, esse mecanismo compromete a ideia de autonomia implícita no conceito de descentralização, mantendo um sobrepoder no nível central do governo.

Para além das instituições oficiais, as organizações sociais também tiveram um papel fundamental no processo de descentralização das estruturas de poder do Estado no Brasil. Isso porque a centralização político-administrativa era vista como um símbolo do autoritarismo estatal, e seu enfraquecimento seria um elemento fundamental para a refundação da democracia no País. Um dos desdobramentos dessa atuação foi a abertura para uma maior participação da população, seja no planejamento, na implementação ou na avaliação das políticas nacionais, tanto diretamente, como por meio de suas organizações representativas. O retorno das instituições democráticas engendrou também um novo cenário para a representação política de diferentes grupos sociais no Brasil, estabelecendo novas relações entre Estado e sociedade.

Nesse contexto, diferentes experiências de participação popular foram desenvolvidas, tais como: conselhos setoriais, fóruns, conferências, audiências públicas e orçamento participativo. Esses espaços se concretizaram enquanto instituições participativas, formalmente organizadas e vinculadas à estrutura de Estado, que definem formas variadas de incorporação de cidadãos na deliberação de políticas públicas, principalmente por meio de suas organizações representativas (AVRITZER, 2010).

\section{As experiências recentes de planejamento territorial no Brasil}

Esse novo contexto econômico e sociopolítico no final do século 20 foi fundamental para possibilitar, no âmbito do Governo Federal, o ressurgimento do debate sobre a definição de diferentes escalas para o planejamento de suas intervenções. As novas bases desse debate chamavam a atenção para a importância de permitir maior flexibilidade para a territorialização da incidência da ação estatal, tendo como influência o acúmulo de experiências sob a abordagem territorial em curso em vários países da União Europeia (UE). Essa abordagem considera o território, definido com base em múltiplas dimensões, como o espaço de mediação social e de incidência de políticas públicas, e, portanto, lócus privilegiado para o planejamento da ação estatal. Além disso, a literatura sobre a temática regional no 
País já destacava há bastante tempo a forte heterogeneidade das macrorregiões brasileiras, que as tornava inadequadas para servirem como referência exclusiva para ações de desenvolvimento regional. Com base nessa nova abordagem, houve um esforço de construir instrumentos e estratégias diferentes que a viabilizassem enquanto um novo paradigma para o planejamento de políticas públicas nacionais (SILVA, 2013a, 2014).

Uma das referências internacionais mais citadas para a implementação de estratégias de planejamento territorial é o programa Ligações entre Ações do Desenvolvimento da Economia Rural (Leader). Esse programa surgiu na Europa em 1991, tendo como principal objetivo apresentar um enfoque multissetorial e integrado para a dinamização de espaços rurais com base em projetos territoriais inovadores. Desde sua constituição, o Programa Leader tem sido considerado o principal instrumento para o desenvolvimento das áreas rurais europeias de natureza integradora, por meio do planejamento e execução de projetos prioritários com base em uma estrutura política ascendente (bottom-up). Os grupos de ação local são os responsáveis pela definição dos territórios do Leader, que contam com uma ampla e diversificada rede política, composta por agências de governo, sindicatos, organizações do setor privado, organizações não governamentais (ONGs) e representantes locais eleitos (SARACENO, 2005; GHESTI; SILVA, 2015).

No Brasil, a CF/1988 estabeleceu a redução das desigualdades regionais como um dos objetivos fundamentais da República Federativa. Vale ressaltar a mudança com relação aos instrumentos estatais de planejamento, com destaque para a instituição do Plano Plurianual de Atividades (PPA). Para subsidiar o processo de regionalização dos investimentos públicos previstos no PPA 1996-1999, o Ministério do Planejamento, Orçamento e Gestão (MPOG) coordenou a elaboração dos estudos sobre os Eixos Nacionais de Integração e Desenvolvimento, considerados por muitos autores como o ponto de partida da retomada da preocupação regional no processo de planejamento estatal no País. Entretanto, poucos resultados concretos foram obtidos a partir desse esforço, de maneira que são muitas as críticas quanto à real contribuição do PPA para a garantia de uma ação territorializada do Governo Federal.

Em 2000, o Ministério da Integração Nacional (MI) elaborou o documento Bases para as Políticas de Integração Nacional e Desenvolvimento Regional, o qual propunha uma série de objetivos amplos para a gestão do território, tais como: promover a competitividade sistêmica; mobilizar o potencial endógeno de desenvolvimento das regiões; fortalecer a coesão econômica e social; promover o desenvolvimento sustentável; e fortalecer a integração continental. Em 2006, o MI apresentou os subsídios para a elaboração da proposta da Política Nacional de Ordenamento Territorial (SILVA, 2012). 
Em consequência desses acontecimentos, o tema das políticas de desenvolvimento regional passou a ganhar espaço na agenda governamental, o que permitiu o surgimento de políticas públicas elaboradas no âmbito federal com base em uma perspectiva territorial. Essas políticas foram se diversificando ao longo do tempo, com relação a desenho institucional, áreas temáticas, recortes territoriais abrangidos, público envolvido etc. Porém, a apropriação do conceito de território, enquanto um instrumento operacionalizador de políticas públicas por parte do Estado, passou a ser realizada de diferentes formas.

Silva (2013a) elaborou uma tipologia que permite uma melhor caracterização dessas formas de abordagem territorial utilizadas pelo poder público no planejamento e na implementação de suas ações. Foram definidas quatro categorias, de acordo com a centralidade que o território possui em cada estratégia e no grau de conflitualidade que apresentam. As categorias definidas são: território como meio, território como fim, território como regulação e território como direito. Cada uma das políticas que se enquadram nessas categorias analíticas possui suas trajetórias e estruturas características, suas dificuldades de implementação, suas vantagens em termos de resultado, seus avanços e contradições na relação com o território. O Quadro 1 apresenta as principais características de cada um deles e alguns exemplos para complementar as informações.

\section{Quadro 1 - Tipos de abordagem territorial nas políticas públicas}

\begin{tabular}{|c|c|c|c|}
\hline Tipo & Definição & Conflituosidade & Exemplos \\
\hline $\begin{array}{l}\text { Território } \\
\text { como } \\
\text { meio }\end{array}$ & $\begin{array}{l}\text { Políticas setoriais que de- } \\
\text { finem recortes territoriais } \\
\text { específicos para alcança- } \\
\text { rem maior efetividade na } \\
\text { sua implementação. }\end{array}$ & Baixa & $\begin{array}{l}\text { Consórcios municipais de } \\
\text { educação e de saúde; uni- } \\
\text { dades de polícia pacificado- } \\
\text { ra (UPPs); Programa Saúde } \\
\text { da Família (PSF). }\end{array}$ \\
\hline $\begin{array}{l}\text { Território } \\
\text { como fim }\end{array}$ & $\begin{array}{l}\text { Políticas baseadas em } \\
\text { estratégias intersetoriais e } \\
\text { articuladas para o desen- } \\
\text { volvimento de territórios } \\
\text { específicos com graves } \\
\text { deficiências estruturais e } \\
\text { alta incidência de pobreza. }\end{array}$ & Média & $\begin{array}{l}\text { Política Nacional de } \\
\text { Desenvolvimento Regional } \\
\text { (PNDR); Programa } \\
\text { Territórios da Cidadania } \\
\text { (PTC). }\end{array}$ \\
\hline $\begin{array}{l}\text { Território } \\
\text { como } \\
\text { regulação }\end{array}$ & $\begin{array}{l}\text { Políticas que se utilizam de } \\
\text { uma abordagem territorial } \\
\text { para estabelecer normati- } \\
\text { zações para o uso público e } \\
\text { privado do espaço geográ- } \\
\text { fico nacional. }\end{array}$ & Média & $\begin{array}{l}\text { Zoneamento Ecológico- } \\
\text { econômico (ZEE); } \\
\text { Plano Regional de } \\
\text { Desenvolvimento da } \\
\text { Amazônia (PRDA). }\end{array}$ \\
\hline
\end{tabular}




\begin{tabular}{|l|l|l|l|}
\hline Tipo & Definição & Conflituosidade & Exemplos \\
\hline \multirow{3}{*}{$\begin{array}{l}\text { Território } \\
\text { como } \\
\text { direito }\end{array}$} & $\begin{array}{l}\text { Políticas que visam assegu- } \\
\text { rar a grupos sociais espe- } \\
\text { cíficos o direito a recursos } \\
\text { territoriais imprescindíveis } \\
\text { para sua reprodução social. }\end{array}$ & \multirow{2}{*}{ Alta } & $\begin{array}{l}\text { Reforma agrária; regulari- } \\
\text { zação de áreas quilombo- } \\
\text { las; demarcação de terras } \\
\text { indígenas. }\end{array}$ \\
\hline
\end{tabular}

Fonte: Silva (2013a).

Neste trabalho, as atenções recaem sobre programas que têm em comum o fato de abordarem o território como fim, isto é, buscam incentivar a elaboração e implementação de projetos de interesse comum entre diferentes unidades federativas mediante um conjunto de regras definidas na esfera nacional, articulando uma série de programas e políticas, de acordo com arranjos institucionais estabelecidos nas diferentes configurações territoriais escolhidas. Entre as políticas recentes que se baseiam nessa abordagem territorial de intervenção, as análises aqui realizadas dizem respeito especificamente à Política Nacional de Desenvolvimento Regional (PNDR).

\section{A Política Nacional de Desenvolvimento Regional (PNDR)}

A PNDR começou a ser implementada em 2003, embora sua institucionalização oficial tenha se dado posteriormente pelo Decreto Presidencial n ${ }^{\circ} 6.047$, de fevereiro de 2007. Ela foi lançada paralelamente ao Pacto para a Gestão Territorial Integrada ${ }^{1}$, previsto na Lei do Plano Plurianual de Atividades (PPA) 2004-2007 (Lei no 10.933, de $11 / 08 / 2004$, art. 12). Sua gestão ficou a cargo do MI, por meio de sua Secretaria de Desenvolvimento Regional (SDR). ${ }^{2}$ Segundo Perico (2009), a instrumentalização da PNDR evidencia a percepção sobre o manejo da escala regional e da territorialização brasileira, com programas e projetos orientados por iniciativas de recorte espacial a partir de critérios específicos.

A PNDR apresenta em seu corpo normativo o reconhecimento de que as desigualdades regionais brasileiras constituem enormes obstáculos ao desenvolvimento do País, o que justifica o estabelecimento de critérios e orientações de atuação articulada entre governos e atores sociais para aproveitar a grande

\footnotetext{
1 "A finalidade do pacto é ampliar o diálogo, de forma sistemática, entre os três entes da Federação em torno de programas e estratégias comuns, que assegurem a continuidade e a efetividade das ações governamentais. Buscase, assim, alinhar de uma forma coerente os projetos de desenvolvimento territorial (uma perspectiva endógena e de planejamento ascendente) com a estratégia de desenvolvimento nacional e de inserção internacional" (BRASIL, 2005, p. 11).

${ }^{2}$ A proposta da PNDR foi elaborada pelo MI e recebeu a chancela do Governo Federal por meio da Câmara de Política de Integração Nacional e Desenvolvimento Regional, composta por representantes de 21 ministérios e do Conselho de Desenvolvimento Econômico e Social (CDES), da Presidência da República (INSTITUTO DE PESQUISA ECONÔMICA APLICADA, 2010a).
} 
diversidade territorial brasileira na busca da redução dessas desigualdades. Com isso, esperava-se apresentar uma estratégia estruturada de ação estatal como alternativa à guerra fiscal e à fragmentação territorial que predominavam no País desde a década de 1980, quando se enfraqueceram as capacidades estatais para o planejamento e o financiamento do desenvolvimento regional. Seus objetivos específicos são: i) dotar as regiões das condições necessárias de infraestrutura, crédito e tecnologia; ii) promover a inserção social produtiva da população, a capacitação dos recursos humanos e a melhoria da qualidade de vida; iii) fortalecer as organizações socioprodutivas regionais, ampliando a participação social; e iv) estimular a exploração das potencialidades que advêm da diversidade socioeconômica, ambiental e cultural do País (SILVA, 2013b).

Para se chegar a esses objetivos, o programa adotou a caracterização das regiões brasileiras e, a partir do cruzamento de variáveis como rendimento domiciliar médio e variação anual média do PIB, caracterizou as microrregiões em quatro tipos: de alta renda, dinâmicas, estagnadas e de baixa renda. As microrregiões de alta renda englobam $54,4 \%$ da população brasileira e concentram $77,2 \%$ do PIB, enquanto as demais regiões representam mais de $70 \%$ da área, abrigam $45,6 \%$ da população e produzem apenas $22,8 \%$ do total das riquezas do País. A maior concentração de microrregiões de menor renda e dinamismo ficou situada nas Regiões Norte e Nordeste. Pelo menos dois aspectos importantes puderam ser evidenciados sobre a necessidade de atuação do Estado em múltiplas escalas territoriais: i) coexistência, em todas as macrorregiões do País, de algumas sub-regiões com elevados rendimentos relativos médios, dinâmicas e competitivas, e outras com precárias condições de vida e traços de estagnação; e ii) presença de microrregiões dinâmicas - do ponto de vista demográfico e de crescimento do PIB - dispersas ao longo de todo o território nacional (INSTITUTO DE PESQUISA ECONÔMICA APLICADA, 2009).

Com base nessa caracterização, foi definida uma tipologia sub-regional a partir da qual o Governo Federal poderia orientar as ações a serem desenvolvidas. Para isso, a PNDR adotou o conceito de mesorregião para seus recortes territoriais, sendo identificadas e homologadas inicialmente pelo $\mathrm{Ml}$ treze mesorregiões prioritárias (mesorregiões diferenciadas). Além do critério microrregional de renda e dinamismo econômico, foram elencadas também algumas regiões especiais para a incidência da PNDR, sendo elas: a Amazônia Legal, as Faixas de Fronteira e o Semiárido Nordestino. ${ }^{3}$

\footnotetext{
${ }^{3}$ Além das mesorregiões, a PNDR prioriza o semiárido e a faixa de fronteira, espaços esses refletidos, de forma específica, na estrutura programática que orienta as ações da secretaria. A Secretaria de Programas Regionais (SPR) dá tratamento especial, ainda, às regiões integradas de desenvolvimento (Rides) de Juazeiro-Petrolina e da Grande Teresina, localizadas nesses espaços prioritários (PEREIRA, 2009, p. 51).
} 
Em termos estratégicos, foram propostos vários programas no PPA 2004-2007 com vistas a dar operacionalidade à PNDR: o Programa de Promoção da Sustentabilidade de Espaços Sub-regionais (Promeso); o Programa de Desenvolvimento Integrado e Sustentável do Semiárido (Conviver); o Programa de Organização Produtiva de Comunidades Pobres (Produzir); o Programa de Promoção e Inserção Econômica de Sub-Regiões (Promover); o Plano de Desenvolvimento Estratégico para o Semiárido (PDSA); o Plano de Desenvolvimento Sustentável para a Área de Influência da Rodovia BR-163; o Plano para a Amazônica Sustentável (PAS); e o Programa de Desenvolvimento das Áreas de Fronteira (PDAF).

Para o desenvolvimento desse rol de programas que compõem a PNDR, um conceitochave utilizado pelo $\mathrm{MI}$ foi o de arranjos produtivos locais (APL), entendidos como conjuntos específicos de atividades econômicas que possuem certo vínculo e podem ser desenvolvidos por aglomerações territoriais de agentes políticos, econômicos e sociais. Em tese, a política definiria critérios objetivos para apoiar APLs que "apresentem potencial significativo em termos de fortalecimento e reestruturação da base econômica e geração de trabalho, emprego e renda" nos territórios envolvidos (BRASIL, 2004, p. 9). No entanto, tais critérios nunca foram de fato definidos.

Entre os mecanismos de governança, a PNDR pautou-se em uma complexa engenharia institucional, resumida por Karam (2012, p. 107) da seguinte forma:

A distribuição de papéis preconizada delega ao nível nacional, composto pelo MI e demais órgãos coordenadores da PNDR, a responsabilidade pela definição de critérios e seleção dos espaços prioritários para alocação de recursos e intervenção de outras políticas. No nível regional caberia, precipuamente, a elaboração de planos estratégicos de desenvolvimento e a articulação de iniciativas e promoção de ações especiais, com destaque para a atuação prevista das novas Sudam, Sudene e Sudeco, consideradas braços de representação da PNDR junto aos atores do território. Já nos níveis inferiores, desdobrar-se-iam as ações propriamente ditas, com ênfase nos programas sub-regionais. Estes são denominados unidades de articulação das ações federais nas sub-regiões, às quais devem acoplar-se espaços institucionais de concertação construídos pelos próprios atores do território, com destaque para os fóruns das mesorregiões diferenciadas e demais instâncias subregionais, cuja composição deve contemplar, além dos órgãos governamentais dos três níveis, setores empresariais e sociedade civil.

Portanto, a ideia foi apresentar uma estrutura de governança que envolvesse diferentes esferas federativas. Na esfera nacional, houve a criação da Câmara de Políticas de Integração Nacional e Desenvolvimento Regional (CPINDR) e o Comitê de Articulação Federativa, ambos instituídos em 2003. A esfera macrorregional baseou-se na proposta de (re)criação das "novas" superintendências regionais de 
desenvolvimento (Sudene, Sudam, Sudeco), que foram beneficiadas pela reorientação dos Fundos Constitucionais de Desenvolvimento (FNE, FNO, FCO, respectivamente). $\mathrm{Na}$ esfera microrregional ou territorial, a estratégia foi criar em cada mesorregião definida pela PNDR um fórum mesorregional, constituídos enquanto "instâncias legítimas de articulação e integração dos atores locais, tanto governamentais quanto não governamentais", que seriam "responsáveis pela identificação, priorização e encaminhamento das demandas locais" (BRASIL, 2004, p. 8). Portanto, tais fóruns foram concebidos na estratégia da política como instrumentos para a articulação institucional entre as diversas instâncias de governo e as organizações da sociedade civil atuantes nos territórios. Dessa forma, eles assumem uma função de destaque na concepção da PNDR, pois representam o eixo no qual as articulações se completam, tanto com vistas às atividades de planejamento e definição de prioridades (ações estratégicas) quanto para o acompanhamento e controle da execução de projetos e programas específicos. O Quadro 2 organiza os diferentes níveis de responsabilidade e participação relativamente à estratégia de governança na PNDR.

\section{Quadro 2 - Instâncias de pactuação da PNDR}

\begin{tabular}{|c|c|c|}
\hline Instância & Composição & Atribuições \\
\hline $\begin{array}{l}\text { Nacional: Câmara } \\
\text { de Políticas de } \\
\text { Integração Nacional } \\
\text { e Desenvolvimento } \\
\text { Regional (CPINDR) e } \\
\text { Comitê de Articulação } \\
\text { Federativa. }\end{array}$ & $\begin{array}{l}\text { A CPINDR é composta por } \\
23 \text { ministérios, represen- } \\
\text { tando ação conjunta do } \\
\text { Governo Federal em áreas } \\
\text { prioritárias, definidas con- } \\
\text { forme critérios da PNDR. } \\
\text { Atua com o Comitê de } \\
\text { Articulação Federativa, for- } \\
\text { mando a escala nacional. }\end{array}$ & $\begin{array}{l}\text { Cabe à escala nacional a definição } \\
\text { de critérios gerais de atuação no } \\
\text { território, identificando as sub-re- } \\
\text { giões prioritárias e os espaços pre- } \\
\text { ferenciais de intervenção da PNDR. }\end{array}$ \\
\hline $\begin{array}{l}\text { Macrorregional: } \\
\text { conselhos delibera- } \\
\text { tivos da Sudene, da } \\
\text { Sudam e da Sudeco, } \\
\text { além da Agência de } \\
\text { Desenvolvimento } \\
\text { da Amazônia (ADA) } \\
\text { e da Agência de } \\
\text { Desenvolvimento do } \\
\text { Nordeste (Adene). }\end{array}$ & $\begin{array}{l}\text { Os conselhos deliberati- } \\
\text { vos da Sudene, Sudam e } \\
\text { Sudeco são integrados por } \\
\text { ministros de Estado, gover- } \\
\text { nadores, representantes } \\
\text { dos prefeitos e represen- } \\
\text { tantes do setor produ- } \\
\text { tivo. Os conselhos são a } \\
\text { instância máxima decisória } \\
\text { desses órgãos. }\end{array}$ & $\begin{array}{l}\text { Nas instâncias macrorregionais, } \\
\text { prevalece a atividade de elabo- } \\
\text { ração dos planos estratégicos de } \\
\text { desenvolvimento, a articulação de } \\
\text { diretrizes e ações de desenvolvi- } \\
\text { mento e a promoção de iniciativas } \\
\text { em territórios priorizados. } \\
\text { Nas macrorregiões Norte, } \\
\text { Nordeste e Centro-Oeste, deve } \\
\text { haver priorização das ações. Nesse } \\
\text { ponto, o Governo Federal conta } \\
\text { com órgãos específicos voltados à } \\
\text { gestão regional, como a ADA e a } \\
\text { Adene, e com a criação das novas } \\
\text { Sudam, Sudene e Sudeco. }\end{array}$ \\
\hline
\end{tabular}




\begin{tabular}{|l|l|l|}
\hline Instância & Composição & Atribuições \\
\hline & & $\begin{array}{l}\text { A unidade de articulação das ações } \\
\text { federais nas sub-regiões selecio- } \\
\text { nadas é conhecida como mesorre- } \\
\text { gião diferenciada. }\end{array}$ \\
& & $\begin{array}{l}\text { Nas instâncias sub-regionais } \\
\text { reside o foco operacional da }\end{array}$ \\
$\begin{array}{l}\text { Mesorregional: fóruns } \\
\text { das mesorregiões }\end{array}$ & Espaços de negociação que & PNDR. São responsáveis pelo \\
diferenciadas e demais & reúnem representantes & pe governos estaduais, \\
instâncias sub-regio- & planejamento, monitoramento e \\
nais de representação & prefeituras, sociedade civil & a avaliação das ações voltadas ao \\
político-institucional. & e setor empresarial. & desenvolvimento. \\
& & Cabe a esses espaços organizar a \\
& mobilização social e a participação, \\
inclusive de setores que geralmen- & te não participam das decisões \\
& sobre políticas públicas. \\
\hline
\end{tabular}

Fonte: Ipea (2010a, p. 227).

No entanto, o desenho institucional da política também acarretou fatores que dificultaram uma ação mais consistente para fomentar novas dinâmicas de desenvolvimento nos territórios diferenciados. Como as mesorregiões são recortes territoriais muito amplos, englobando inclusive diferentes estados em uma única mesorregião, tornou-se difícil a coordenação e operacionalização de projetos conjuntos no interior desses territórios.

Quanto à estrutura de financiamento, a estratégia da PNDR foi montada com base na articulação de recursos do Orçamento-Geral da União (OGU) e dos entes federativos, além de incentivos fiscais já existentes. Além desses instrumentos, os fundos constitucionais geridos pelo Banco da Amazônia (FNO), Banco do Nordeste (FNE) e Banco do Brasil (FCO) também são fontes centrais de recursos para o desenvolvimento regional no País. Seus recursos têm origem no Imposto de Renda (IR) e no Imposto sobre Produtos Industrializados (IPI), além de outras fontes. Tais recursos são transferidos aos bancos que operam empréstimos aos empreendedores locais, via MI, no intuito de gerar novas oportunidades produtivas nas regiões. O Banco Nacional de Desenvolvimento Econômico e Social (BNDES) também criou linhas de financiamento para programas regionais, entre os quais se incluem: o Programa Nordeste Competitivo (PNC), o Programa Amazônia Integrada (PAI), o Programa de Fomento e Reconversão Produtiva da Metade Sul do Rio Grande do Sul (Reconversul) e o Programa do Centro-Oeste (PCO). Entretanto, alguns autores chamaram a atenção para incongruências em termos de efetivação 
dos empréstimos com recursos dos fundos constitucionais. Entre elas, está o fato de serem direcionados a municípios e estados mais dinâmicos no interior das regiões. Assim, os fundos constitucionais de financiamento reforçam ainda mais "a tendência de concentração dos investimentos privados nas áreas mais dinâmicas de cada região", o que contribui para o aumento das disparidades intrarregionais (INSTITUto de Pesquisa EConômica Aplicada, 2012, p. 141-145).

Na prática, o que se verificou relativamente ao financiamento do desenvolvimento regional foi a desproporção entre a dimensão das desigualdades enfrentadas desde a construção da PNDR e o fluxo de recursos disponíveis (INSTITUTO DE PESQUISA ECONÔMicA AplicAdA, 2009). Houve, ao longo dos anos, uma alta dependência de recursos da União, dada a estrutura fiscal brasileira. Nesse sentido, o financiamento do programa se tornou refém das diretrizes gerais da política fiscal estabelecidas pelo Governo Federal, que definem tanto a dotação orçamentária anual para cada programa, como as porcentagens de contingenciamento dos recursos, a fim de alcançar as metas fiscais definidas pelo Ministério da Fazenda para cada ano. Com a PNDR não foi diferente.

Como exemplo, pode-se observar a trajetória de execução orçamentária do Promeso, que, entre os programas que compunham a PNDR, foi o que recebeu maior dotação orçamentária ao longo dos anos, desde sua inserção no PPA 2004-2007 (Programa $\mathrm{n}^{\circ} 1.025$ do MI). Seu objetivo é "aumentar a autonomia e a sustentabilidade de espaços sub-regionais por meio da organização social, do desenvolvimento do seu potencial endógeno e do fortalecimento da sua base produtiva, com vistas à redução das desigualdades regionais" (BRASIL, 2004, p. 6). Percebe-se, pela Tabela 1, que o Promeso obteve um salto significativo de recursos orçamentários a partir de 2007, ano em que se institucionalizou a PNDR. Nos anos seguintes, referentes ao PPA 2008-2011, o programa foi apresentando queda nos valores totais, recuperando-se significativamente em 2010, ano com o maior valor orçamentário obtido. Quanto à porcentagem de recursos executados, o maior valor ocorreu em 2006 , com $75,4 \%$. Nos anos seguintes, em que houve aumento dos recursos, a execução não aumentou no mesmo ritmo, não chegando a 60\% em 2008 e 2009, e caindo drasticamente em 2010 para menos de 15\% de execução. Desse modo, o ano com maior volume de recursos foi também o de menor execução orçamentária. A baixa execução em 2010 é observada, sobretudo, na principal ação do Promeso (6.409 - Apoio à implantação de infraestrutura social e produtiva), que, nesse ano, apresentava dotação de quase $\mathrm{R} \$ 195$ milhões ( $40 \%$ do total), mas teve execução inferior a $2 \%$. 
Tabela 1 - Dados de execução orçamentária do Promeso (2004-2010 - valores correntes)

\begin{tabular}{l|l|l|l|l|l|l|l}
\hline Ano & 2004 & 2005 & 2006 & 2007 & 2008 & 2009 & 2010 \\
\hline $\begin{array}{l}\text { a) Dotação } \\
\text { orçamentá- } \\
\text { ria (R\$ mil) }\end{array}$ & 120.789 & 165.502 & 163.617 & 379.829 & 340.698 & 306.683 & 487.707 \\
\hline $\begin{array}{l}\text { b) Total } \\
\text { liquidado } \\
\text { (R\$ mil) }\end{array}$ & 75.221 & 122.617 & 123.348 & 218.146 & 203.094 & 179.948 & 69.687 \\
\hline $\begin{array}{l}\text { Execução } \\
(b / a, \%)\end{array}$ & 62,3 & 74,1 & 75,4 & 57,4 & 59,6 & 58,7 & 14,3 \\
\hline
\end{tabular}

Fonte: Câmara dos Deputados. Disponível em: <http://www2.camara.leg.br/atividade-legislativa/orcamentobrasil/ orcamentouniao/loa/loa-2014 >.

Não é objetivo deste trabalho se aprofundar nas análises dos determinantes da baixa execução desse programa e dos demais que compõem o leque de alternativas da PNDR. Porém, isso demonstra que, para a efetivação dos grandes objetivos iniciais que a política previa em termos de combate às desigualdades regionais do País, não foram viabilizados os instrumentos orçamentários e estruturais necessários. Ademais, como destacou o Ipea (2010a), esses programas são muito sensíveis à determinação de reservas de contingência orçamentária pelo Governo Federal.

Um dos possíveis entraves para a melhor execução dos recursos do Promeso é a baixa efetividade dos fóruns mesorregionais, o que impediu uma maior articulação política de apoio a projetos estratégicos nas mesorregiões. Poucos deles funcionaram como se esperava. A falta de previsão de recursos, pelo menos em um período inicial de implementação da política, para custear reuniões e mobilizações dessas instâncias, e também a ausência de um calendário sistemático do ciclo anual de investimentos do programa para imprimir uma agenda a esses fóruns comprometeram bastante a criação de uma ação mais propositiva. Atualmente, os fóruns encontram-se sem função ou foram inseridos em fóruns e conselhos intermunicipais de outros programas.

No que diz respeito à distribuição regional desses recursos, o Gráfico 1 mostra os resultados anuais em termos de participação percentual de cada região no montante aplicado; e o Gráfico 2 traz a porcentagem de cada região no total aplicado em todo o período. Pode-se verificar que, com exceção de 2004 , quando a Região Sul teve o maior volume de recursos, a Região Nordeste recebeu a maior parcela dos recursos nos demais anos, totalizando $51 \%$ dos recursos no período. Um destaque a se considerar é o crescimento dos recursos aplicados na Região Centro-Oeste, que, entre 2004 e 2006, não chegaram a atingir 1\%, porém em 2010 
foram responsáveis por $30 \%$ dos recursos do programa, totalizando $9 \%$ na soma do período. A Região Norte respondeu por apenas $4 \%$ dos recursos no período, ficando então com a menor parcela dos investimentos.

\section{Gráfico 1 - Recursos do Promeso por ano e por região (2004-2010) - (Em \%)}

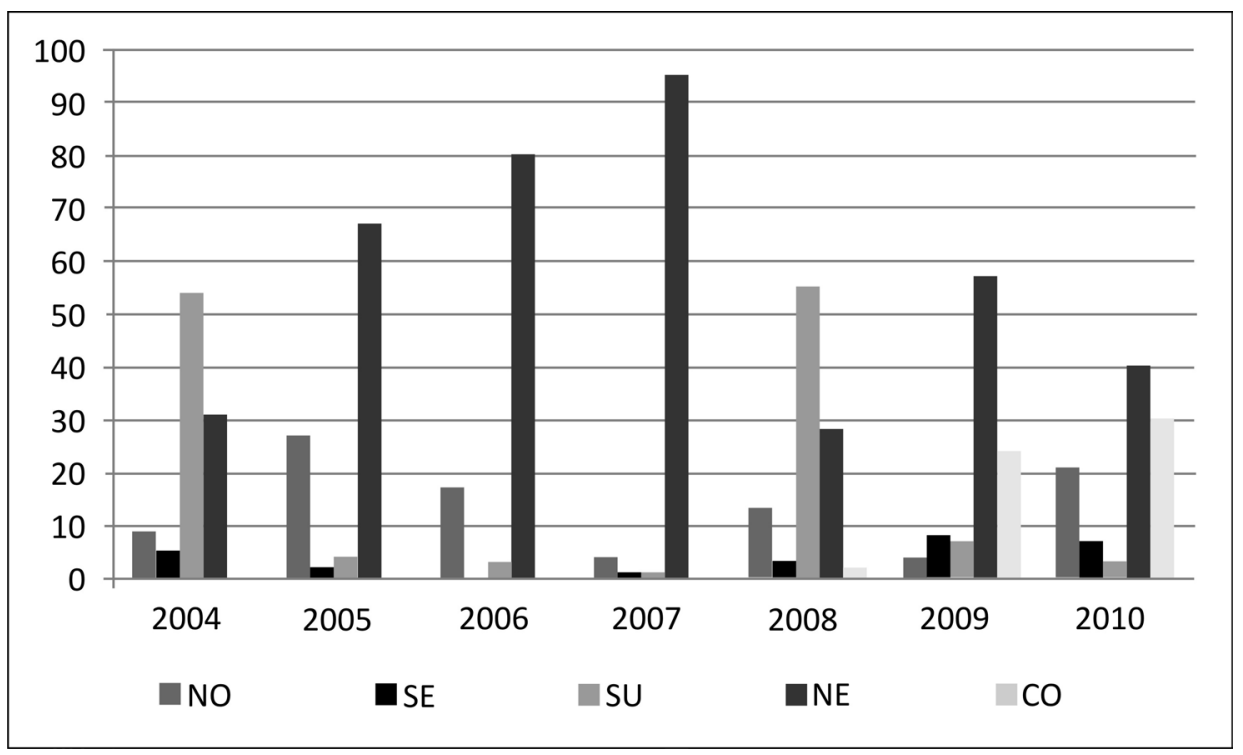

Fonte: Câmara dos Deputados. Disponível em:<http://www2.camara.leg.br/atividade-legislativa/orcamentobrasil/ orcamentouniao/loa/loa-2014 >.

\section{Gráfico 2 - Recursos do Promeso por região (2004-2010) - (Em \%)}

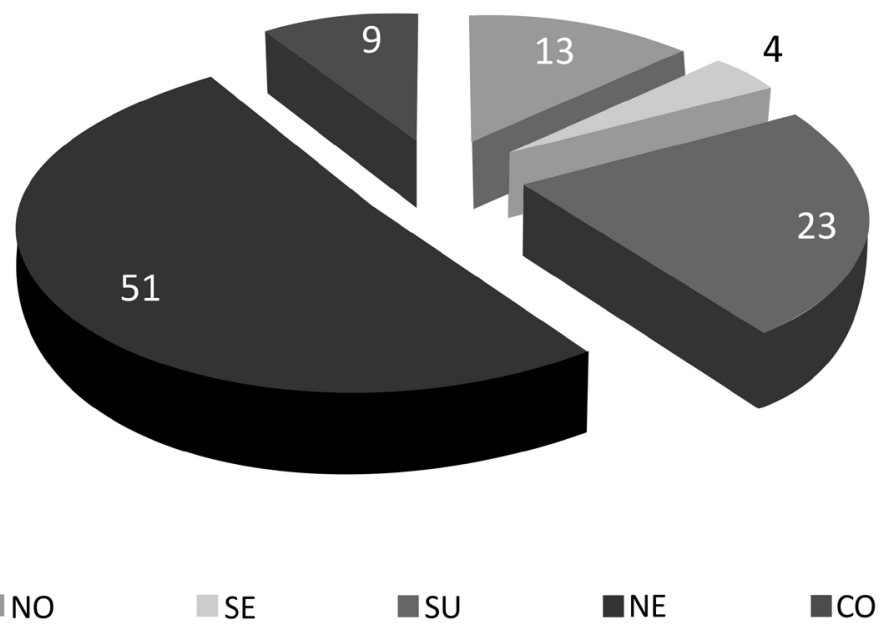

Fonte: Câmara dos Deputados. Disponível em:< http://www2.camara.leg.br/atividade-legislativa/orcamentobrasil/ orcamentouniao/loa/loa-2014 > 
Esse cenário de incertezas quanto à disponibilidade de recursos regulares já havia sido previsto pela equipe de elaboração da proposta inicial da PNDR, liderada pela estudiosa da economia regional brasileira Tânia Bacelar Araújo. Por isso, um dos pilares da proposta para a viabilização da PNDR foi a constituição do Fundo Nacional de Desenvolvimento Regional (FNDR), aos moldes do Fundo Europeu de Desenvolvimento Regional (Feder), fundo próprio da União Europeia para o financiamento de projetos no âmbito do Programa Leader. Seu caráter estratégico se justifica por cumprir uma função que vai além de ser uma fonte de financiamento, visto que também teria como função adequar os instrumentos de financiamento existentes a uma nova abordagem territorial para os investimentos públicos.

De acordo com a proposta do Governo Federal para o FNDR, incluída nas negociações da reforma tributária, ele cobriria essencialmente projetos de infraestrutura econômica de pequena e média escala e seria constituído por $4,8 \%$ do produto da arrecadação dos seguintes impostos: i) Imposto de Renda de Pessoas Jurídicas (IRPJ); ii) Imposto sobre Produtos Industrializados (IPI); iii) Imposto sobre Grandes Fortunas (IGF) - ainda não regulamentado; iv) Imposto sobre Operações com Bens e Prestação de Serviços, novo imposto que se propõe para substituir o Programa de Integração Social (PIS), a Contribuição para o Financiamento da Seguridade Social (Cofins), a Contribuição de Intervenção no Domínio Econômico (Cide) e a contribuição sobre folha para o salário-educação; e v) outros impostos que venham a ser criados (PEREIRA, 2009).

Porém, o FNDR não foi criado, devido às várias tentativas frustradas de reforma tributária desde 2003. De acordo com Pereira (2009, p. 176), o ponto central do debate sobre do FNDR ocorreu em torno da "questão da partilha federativa de tributos, ou seja, sobre quem vai ganhar ou perder recursos com a reforma". A dificuldade de cooperação federativa, sobretudo em um tema tão delicado quanto a reforma tributária, impediu a viabilização de um novo instrumento de financiamento para uma política nacional que visava justamente apresentar uma estratégia de coordenação vertical para políticas de desenvolvimento regionalmente equilibrado no Brasil.

Por fim, vale destacar que, a exemplo de outras políticas públicas do Governo Federal, o MI iniciou em 2012 o processo para a realização da I Conferência Nacional de Desenvolvimento Regional (CNDR), no intuito de garantir um novo canal para a participação dos diversos setores sociais nas discussões sobre desenvolvimento regional no País. Seus eixos temáticos foram: i) governança, participação social e diálogo federativo; ii) financiamento do desenvolvimento regional; iii) desigualdades regionais e critérios de elegibilidade; e $i v$ ) vetores de desenvolvimento regional sustentável. Com isso, o objetivo desse evento foi a definição de princípios, diretrizes e prioridades para a reformulação da PNDR, a partir da experiência vivida nos 10 anos iniciais do programa. 


\section{Limites operacionais e entraves federativos à PNDR}

Ao avaliar o histórico de implementação da PNDR, pôde-se perceber que algumas questões normativas ainda não estão bem definidas para a institucionalização de programas de articulação territorial dessa natureza, o que acarreta sérios limites operacionais para sua gestão. Grande parte desses limites esbarra no próprio federalismo brasileiro. Para Pereira (2009, p. 115), a dificuldade central desse modelo, com vistas a incorporar o ideal definido na CF/1988, ${ }^{4}$ reside na opção do Estado por um modelo de "federalismo simétrico" em uma "federação assimétrica", o que impede a constituição de um "federalismo cooperativo" de fato. ${ }^{5}$

Nesse caso, os projetos passam a depender da capacidade e do interesse de gestores locais, de modo que mudanças de gestão próprias do ciclo político podem lançar por terra toda uma pactuação previamente elaborada em nome de um projeto territorial. Como os processos eleitorais ocorrem em intervalos curtos no Brasil, tais pactuações se tornam frágeis por natureza, pois nada garante que os novos governantes honrarão os acordos firmados pelas administrações anteriores. Essa questão se reflete também na liberação do financiamento público. O que se observa é que as regras de gestão administrativa das contas públicas e a complexidade das dinâmicas estabelecidas por esses programas acarretam um tempo excessivo para a liberação dos recursos, comprometendo a execução dos projetos aprovados nos territórios.

Uma tentativa de proporcionar elementos jurídicos para a cooperação e a coordenação federativa na operacionalização de políticas e serviços públicos no Brasil foi a Lei $n^{\circ}$ 11.107/2005, a Lei dos Consórcios (LC). Segundo o Ipea (2010b, p. 555), os consórcios são pensados fundamentalmente como "meios para os pequenos municípios prestarem serviços que, dada a escala de investimentos, não seriam economicamente viáveis se oferecidos isoladamente". Em 1998, a EC n 19 proporcionou um reforço jurídico para a superação da fragilidade institucional de arranjos cooperativos desse tipo. Mas foi com a promulgação da Lei Federal $\mathrm{n}^{\circ}$ 8.080/1990, que instituiu o Sistema Único de Saúde (SUS) e abriu espaço para o estabelecimento de consórcios intermunicipais para a prestação desse serviço, que os consórcios se proliferaram em todo o País.

\footnotetext{
${ }^{4}$ A Carta Constitucional de 1988 concedeu tratamento privilegiado sem precedentes às desigualdades regionais brasileiras. Em seu inciso III do artigo $3^{\circ}$, do título I, a Carta expressou claramente que é objetivo fundamental da República Federativa do Brasil "erradicar a pobreza e a marginalização e reduzir as desigualdades sociais e regionais" (BRASIL, 1988).

${ }^{5} \mathrm{O}$ "federalismo cooperativo" é caracterizado por formas de ação conjunta entre esferas de governo, em que as unidades subnacionais mantêm significativa autonomia decisória e capacidade de autofinanciamento.
} 
A LC de 2005 foi importante no sentido de revestir esses consórcios de maior legitimidade jurídica enquanto pessoas de direito público. Almejou-se facilitar a gestão pública em pequenos municípios e permitir que eles trabalhem em parceria, visando assim aperfeiçoar e potencializar suas capacidades técnica, gerencial e financeira, bem como permitir a assinatura de convênios de forma direta com outras entidades de governo. Entretanto, além de ser um instrumento ainda pouco utilizado para constituir novas institucionalidades capazes de protagonizar ações intermunicipais de desenvolvimento, os consórcios públicos, por serem pessoas jurídicas formadas exclusivamente por entes da Federação, dependem diretamente dos interesses dos governantes eleitos, o que implica os mesmos problemas anteriores à própria lei. Além disso, uma das críticas mais frequentes à LC remete à regra imposta em seu regulamento que exige a regularidade fiscal de todos os entes consorciados para a assinatura de um convênio que estabeleça transferência de recursos da União ao consórcio. Dado o cenário federal de fortes desigualdades no Brasil, uma regra como essa compromete a proliferação de consórcios, uma vez que um único município pode inviabilizar a possibilidade de repasse de recursos de toda uma região.

Por fim, sobre a questão do financiamento, não se constituiu nenhum instrumento novo que garantisse o apoio financeiro a projetos inovadores, com critérios claros e objetivos. O esforço mais consistente que houve nessa direção foi a tentativa de se criar o FNDR, que esbarrou novamente nas amarras federativas do País, bem como na falta de prioridade que ele angariou por parte do Executivo federal. Os próprios investimentos dos Fundos Constitucionais, que foram adotados como elementos estratégicos para a operacionalização da PNDR, não conseguiram orientar seus recursos para microrregiões classificadas pelo $\mathrm{MI}$ como de baixa renda ou estagnada. Em 2009 e 2010, por exemplo, os dados oficiais (BRASIL, 2012) apontaram que mais da metade dos investimentos foram destinados a projetos localizados em municípios de microrregiões de maior dinamismo econômico, o que contraria o objetivo de utilizar essas estruturas públicas de financiamento para auxiliar no maior equilíbrio regional de investimentos no País.

Além desse ponto, Araújo (2010, p. 47) chamou a atenção também para o peso atual das emendas parlamentares no esquema de financiamento. Se, por um lado, essas emendas garantem a injeção de recursos para o financiamento público nos territórios, por outro, elas ignoram toda a estratégia participativa e dialogada da definição de prioridades, uma vez que a ligação política dos parlamentares tende a passar por fora das instâncias colegiadas para a aprovação de seus projetos de interesse. Isso evidencia que um modelo de financiamento mais estável é fundamental à sustentabilidade de uma experiência dessa natureza. 


\section{Conclusão}

Este trabalho buscou analisar os principais elementos contidos no desenho institucional da PNDR, bem como alguns de seus entraves operacionais. O que se observou é que a PNDR foi elaborada com base em uma complexa e arrojada engenharia institucional, composta por um mosaico de programas com diferentes estratégias de intervenção e com recortes territoriais de incidência distintos. A adoção de novas escalas para o planejamento e execução de projetos - como no caso das mesorregiões diferenciadas - a partir de critérios técnicos e bem definidos para todo o território nacional também foi um ponto a ser destacado no desenho da política, no intuito de detectar dinâmicas de desenvolvimento e/ou estagnação em diferentes contextos microrregionais do País com vistas a balizar a ação governamental para o desenvolvimento regional.

A principal novidade expressa pela PNDR, além de trazer de volta a temática do desenvolvimento regional à agenda pública, foi o fato de ser a primeira experiência verdadeiramente nacional de desenvolvimento regional, isto é, com foco de atuação diferenciada de acordo com as realidades inter-regionais e intrarregionais em todo o território brasileiro. Até então, as ações governamentais de desenvolvimento regional se restringiam a uma região específica, desconectando-se do caráter global do desenvolvimento brasileiro, e se voltavam a favorecer elites locais.

No entanto, alguns entraves operacionais foram identificados na condução da PNDR durante o período analisado. O principal deles refere-se à própria fragilidade dos instrumentos de cooperação e coordenação entre as unidades subnacionais. A descentralização administrativa, por si só, não apenas não resolve os problemas existentes da relação entre as diferentes esferas de poder federativo (União, Estados e Municípios), como pode propiciar o surgimento de novos conflitos. Isso mostra que a realização de um processo de descentralização deve ser pensada enquanto um projeto que exige planejamento, investimento e acompanhamento, o que não ocorreu no Brasil após a CF/88.

A questão dos mecanismos de financiamento das ações e projetos previstos também se evidenciou como um entrave para sua operacionalização, sobretudo no que se refere à desproporção entre a dimensão das desigualdades enfrentadas desde a construção da PNDR e o fluxo de recursos orçamentários disponibilizados. $\mathrm{O}$ financiamento dos projetos ficou à mercê das diretrizes gerais da política fiscal estabelecidas pelo Governo Federal, sem uma fonte autônoma que garantisse um fluxo constante de recursos, como era a proposta da constituição do fundo (o FNDR) que acabou não se concretizando. Com isso, a capacidade de execução orçamentária do Ministério da Integração Nacional foi baixa ao longo dos anos, em referência aos totais orçados. 
Outra deficiência refere-se à instrumentalização do conceito de APL para a priorização de projetos a serem financiados. Não houve, de fato, a definição de critérios objetivos para o apoio a projetos ligados a APLs com potencial de transbordamentos positivos nos territórios em termos de geração de renda e inovação. Na prática, o financiamento de projetos ocorreu mais sob mecanismos políticos e interesses de alguns grupos setoriais, do que por critérios necessariamente técnicos e de relevância socioeconômica, o que reforça a prática da velha lógica clientelista na alocação de recursos.

As estruturas de governança pensadas nos diferentes territórios de incidência, no contexto da PNDR, também foram pouco efetivas, o que impediu uma maior articulação política de apoio a projetos estratégicos nas mesorregiões. Poucos fóruns mesorregionais tiveram uma vida ativa, no sentido de congregar diferentes forças sociais para elaborar e implementar um plano de desenvolvimento territorial. A carência de uma institucionalidade jurídica própria para seu reconhecimento enquanto unidade de gestão social e a falta de recursos para garantir o cumprimento de uma agenda mínima de mobilização e animação também contribuem para sua baixa efetividade.

Por fim, conclui-se que a experiência da PNDR no Brasil pode trazer importantes ensinamentos em termos de arranjos institucionais e federativos necessários para planejar e implementar uma política de desenvolvimento regional voltada para todo o território nacional. Embora ela não tenha alcançado toda a magnitude esperada em termos de resultados, dados os desafios que uma ação estatal dessa natureza tende a enfrentar - ainda mais em um país com disparidades regionais tão acentuadas como o Brasil - e a ousadia dos objetivos inicialmente propostos, os processos instituídos em torno da política constituem um material importante de análise para o próprio aperfeiçoamento de seus instrumentos institucionais de implementação. A abertura para um maior debate público sobre o tema e da política em si, com a ocorrência da I CNDR em 2012, pode ser um ponto de partida para a reformulação de seus marcos normativos e para a mobilização de novas forças sociais e políticas em torno do tema, no intuito de fortalecê-lo enquanto ponto permanente na agenda governamental.

\section{Referências bibliográficas}

AfFonso, Rui de Britto Álvares. Descentralização e reforma do Estado: a Federação brasileira na encruzilhada. Revista de administração pública, n. 14, 2000.

AMARAL FILHO, Jair. A endogeneização no desenvolvimento econômico regional. In: Encontro Nacional De Economia, 27., 1999. Anais... Belém: ANPEC, 1999.

ARAúso, Tânia Bacelar. Pensando o futuro das políticas de desenvolvimento territorial 
no Brasil. In: Miranda, Carlos; Tibúrcio, Breno. Políticas de desenvolvimento territorial no Brasil: avanços e desafios. Brasília: Nead, 2010.

ARRETCHE, Marta. Federalismo e políticas sociais no Brasil: problemas de coordenação e autonomia. São Paulo em perspectiva, v. 18, n. 2, 2004.

AVritzer, Leonardo. A dinâmica da participação local. São Paulo: Cortez, 2010.

BRANDÃo, Carlos. Territórios com classes sociais, conflitos, decisão e poder. In: ORTEGA, Antônio; FILHo, Niemeyer (Org.). Desenvolvimento territorial: segurança alimentar e economia solidária. Campinas: Alínea, 2007.

BRASIL. Programas de desenvolvimento regional: PPA 2004-2007. Brasília: MI, 2004. Pactos para a Gestão Territorial Integrada. Brasília: MPOG, 2005.

Decreto no 6.047, de 2007.

Política Nacional de Desenvolvimento Regional. IICA: MI, 2008.

Ministério da Integração Nacional, Secretaria de Fundos Regionais e Incentivos Fiscais. Fundos regionais e incentivos fiscais. Publicação anual - 2012.

CRocomo, Francisco C.; GUILноTo, Joaquim J. M. Interação dos setores econômicos entre as grandes regiões brasileiras em 1985. In: ENCONTRO NACIONAL DE ECONOMIA, 26., 1998. Anais... Vitória: ANPEC, 1998.

FALLETI, Tulia. Efeitos da descentralização nas relações intergovernamentais: o Brasil em perspectiva comparada. Sociologias, n. 16, 2006.

Furtado, Celso. Formação econômica do Brasil. São Paulo: Nacional, 2003.

GALVÃo, Antônio C.; VASCONCELOS, Ronaldo. Política regional à escala sub-regional: uma tipologia territorial como base para um fundo de apoio ao desenvolvimento regional. Texto para Discussão, no 665. Brasília: Ipea, 1999.

GHESTI, João Paulo; SILVA, Sandro Pereira. A abordagem territorial do programa Leader na Europa e sua transferência institucional ao contexto latino-americano: uma análise crítica. Boletim Regional e Urbano, Ipea, 2015.

GoMIDE, Alexandre A. A gênese das agências reguladoras de transporte: o institucionalismo histórico aplicado à reforma regulatória brasileira dos anos de 1990. Texto para Discussão, no 1764. Brasília: Ipea, 2012.

GUIMARÃES NETO, Leonardo. Antecedentes e evolução do planejamento territorial no Brasil. In: Mirand, Carlos; TıBúrcio, Breno. Políticas de desenvolvimento territorial no Brasil: avanços e desafios. Brasília: Nead, 2010.

INSTITUTO DE PESQUISA ECONÔMICA APLICADA (IPEA). Os desequilíbrios regionais e a política nacional de desenvolvimento regional. In: INSTITUTO DE PESQUISA ECONÔMICA APLICADA (IPEA). Brasil em desenvolvimento 2009. Brasília: Ipea, 2009. v. 2.

Ipea, 2010a. v. 2.

Estrutura produtiva avançada e regionalmente integrada. Brasília:

Brasil em desenvolvimento 2010. Brasília: Ipea, 2010b. v. 3.

Brasil em desenvolvimento 2011. Brasília: Ipea, 2012. v. 1.

KARAM, Ricardo A. A economia política do desenvolvimento territorial: uma análise da diversidade institucional na agenda brasileira. 2012. Tese (Doutorado) Universidade Federal do Rio de Janeiro, Rio de Janeiro, 2012. 
Minduln, Betty. Planejamento no Brasil. São Paulo: Perspectiva, 2003.

Pereira, Priscila de Góes. Dificuldades de implementação da Política Nacional de Desenvolvimento Regional (PNDR). Rio de Janeiro: UFRJ, 2009. Dissertação (Mestrado) -Universidade Federal do Rio de Janeiro, Rio de Janeiro, 2009.

PERICO, Rafael E. Identidade e território no Brasil. Brasília: IICA, 2009.

SANTOS, Milton. Metamorfoses do espaço habitado. São Paulo: Hucitec, 1988.

SARACENO, Elena. Las políticas de desarrollo rural en los procesos de modernización. In: Seminário Nacional de Desenvolvimento Rural Sustentável. Brasília, 2005.

SILVA, Sandro Pereira. Território e estruturas de mercado para produtos tradicionais: o caso da produção familiar de cachaça no território Alto Rio Pardo (MG). Revista Isegoria, v. 1, n. 2, p. 85-99, set. 2011-fev. 2012. Disponível em: <http://tinyurl.com/ m4c3sns>.

Considerações analíticas e operacionais sobre a abordagem territorial em políticas públicas. In: INSTITUTO DE PESQUISA ECONÔMICA APLICADA (IPEA). Brasil em Desenvolvimento 2013 (v. 1). Brasília: Ipea, 2013a.

Avanços e limites da implementação de políticas públicas nacionais sob a abordagem territorial no Brasil. Texto de Discussão, n. 1898. Brasília: Ipea, 2013b.

Mediação social e incidência territorial de políticas públicas de desenvolvimento rural no Médio Jequitinhonha/MG. Revista Cadernos Gestão Pública e Cidadania. FGV: São Paulo, 2014.

\section{Sandro Pereira da Silva}

Técnico de Planejamento e Pesquisa do Instituto de Pesquisa Econômica Aplicada (Ipea). Bacharel e Mestre em Economia pela Universidade Federal de Viçosa (UFV). Doutorando em Políticas Públicas pela Universidade Federal do Rio de Janeiro (UFRJ).

Contato: sandroecbr@yahoo.com.br 